\title{
Insulin-like growth factor-1 and 17 $\beta$-estradiol down-regulate prostate apoptosis response-4 expression in MCF-7 breast cancer cells
}

\author{
DEBORA A. CASOLARI, MICHELLY C. PEREIRA, SIMONE A. DE BESSA GARCIA and MARIA A. NAGAI
}

Disciplina de Oncologia, Departamento de Radiologia da Faculdade de Medicina

da Universidade de São Paulo, 01246-903 Sao Paulo, Brazil

Received February 16, 2011; Accepted March 29, 2011

DOI: $10.3892 / \mathrm{ijmm} .2011 .691$

\begin{abstract}
The PKC apoptosis WT1 regulator gene, also named prostate apoptosis response-4 (PAR-4), encodes a pro-apoptotic protein that sensitizes cells to numerous apoptotic stimuli. Insulin-like growth factor-1 (IGF-1) and $17 \beta$-estradiol (E2), two important factors for breast cancer development and progression, have been shown to downregulate PAR-4 expression and inhibit apoptosis induced by PAR-4 in neuronal cells. In this study, we sought to investigate the mechanisms of regulation of PAR-4 gene expression in MCF-7 cells treated with E2 or IGF-1. E2 (10 nM) and IGF-1 (12.5 nM) each down-regulated PAR-4 expression in MCF-7 cells after $24 \mathrm{~h}$ of treatment. The effect of E2 was dependent on ER activation, as demonstrated by an increase in PAR-4 expression when cells were pretreated for $1 \mathrm{~h}$ with $1 \mu \mathrm{M}$ ICI-182,780 (ICI) before receiving E2 plus ICI. The effect of IGF-1 was abolished by pre-treatment for $1 \mathrm{~h}$ with $30 \mu \mathrm{M}$ LY294002 (a specific PI3-K inhibitor), and significantly inhibited by $30 \mu \mathrm{M}$ SB202190 (a specific p38MAPK inhibitor). We also demonstrated that E2 acts synergistically with IGF-1, resulting in greater down-regulation of PAR-4 mRNA expression compared with E2 or IGF-1 alone. Our results show for the first time that E2 and IGF-1 inhibit PAR-4 gene expression in MCF-7 cells, suggesting that this down-regulation may provide a selective advantage for breast cancer cell survival.
\end{abstract}

\section{Introduction}

The PKC apoptosis WT1 regulator gene, also known as prostate apoptosis response-4 (PAR-4), was first found to be

Correspondence to: Dr Maria A. Nagai, Disciplina de Oncologia, Departamento de Radiologia da Faculdade de Medicina da Universidade de São Paulo, Av. Dr Arnaldo, 455, $4^{\circ}$ andar, 01246-903 Sao Paulo, Brazil

E-mail: nagai@usp.br

Key words: breast cancer, estrogen, estrogen receptor, prostate apoptosis response-4, insulin-like growth factor-1 up-regulated in prostate cancer cells induced to undergo apoptosis (1). PAR-4 is down-regulated in renal cell carcinoma (2), neuroblastoma (3), acute lymphatic leukemia, and chronic lymphocytic leukemia (4). The PAR-4 protein is ubiquitously expressed and is localized in the cytoplasm of diverse normal tissues and cell lines, as well as in both the cytoplasm and the nucleus of many tumors and cancer cells (5-7). A recent study provides evidence that PAR-4 is also secreted by cells, and therefore is also present in the extracellular compartment (cell culture conditioned medium or circulating in serum) (8). Its expression sensitizes numerous cell types to apoptosis in response to diverse apoptotic stimuli (such as intracellular calcium elevation, TNF $\alpha$, doxorubicin, or growth factor withdrawal), but is not sufficient to induce apoptotic cell death $(6,9)$. The mechanism of PAR-4 apoptosis induction involves the translocation of Fas/FasL to the plasma membrane (10), phosphorylation of the SAC domain, as well as nuclear translocation $(9,11)$ and inhibition of the pro-survival factor $\mathrm{NF}-\kappa \mathrm{B}$ $(12,13)$.

Breast cancer is the primary cause of cancer-related death in women $(14,15)$. Estrogens and growth factors, such as the insulin-like growth factor-1 (IGF-1) are important for the maintenance of mammary gland homeostasis, and alterations in these signaling factors' pathways have been implicated in breast cancer development and progression. The activity of $17 \beta$-estradiol (E2) is mediated by estrogen receptors (ERs), which are transcription factors that can be activated through ligand-dependent and -independent mechanisms to regulate the expression of ER-target genes $(16,17)$. Prolonged exposure to $\mathrm{E} 2$ is an important risk factor for breast cancer development. In fact, some studies have shown that E2 induces the proliferation of ER-positive breast cancer cells through the transcriptional regulation of estrogen-responsive genes involved in cell cycle control (18-20). The IGF-1 pathway regulates proliferation and cell survival. IGF-1 induces the proliferation of breast cancer cell lines (21), and IGF-1 receptor (IGF-1R) over-expression in a transgenic mouse model was sufficient to induce mammary gland hyperplasia and tumor formation (22). IGF-1 can also activate the ER in a ligand-independent way to stimulate cell proliferation through the ER pathway (23). In addition, ER activation increases the expression of some signaling proteins from the IGF pathway (24), and 
simultaneous stimulation with IGF-1 and E2 results in a synergistic or additive effect on the cell response. IGF-1 and E2 have been shown to down-regulate PAR-4 expression and inhibit apoptosis induced by PAR-4 in neuronal cells $(25,26)$.

Recently, we have demonstrated that reduced nuclear expression of PAR-4 is associated with poor breast cancer prognosis (27); however, little is currently known regarding the role of PAR-4 in breast cancer tumorigenesis. In the present study, we investigated the regulation of PAR-4 gene expression by $\mathrm{E} 2$ and IGF-1 in the MCF-7 breast cancer cell line. We report for the first time that E2 and IGF-1 inhibit PAR-4 expression, that the effects of estrogen are perpetuated via the ER, and that E2 and IGF-1 act synergistically to down-regulate PAR-4 expression. Although further studies are required, our results suggest that down-regulation of PAR-4 expression by the mitogenic factors E2 and IGF-1 leads to inhibition of PAR-4 expression, which may provide a selective survival advantage for breast cancer cells.

\section{Materials and methods}

Cell line, culture conditions and treatments. MCF-7 cells were obtained from the American Type Culture Collection (ATCC). MCF-7 cells were maintained in RPMI-1640 medium (Sigma Corp.) supplemented with $100 \mathrm{U} / \mathrm{ml}$ penicillin, $100 \mu \mathrm{g} / \mathrm{ml}$ streptomycin, $0.25 \mu \mathrm{g} / \mathrm{ml}$ fungizone, and $10 \%$ fetal bovine serum (FBS) (Invitrogen Life Technologies) in a humidified atmosphere of $5 \% \mathrm{CO}_{2}$. Forty-eight hours prior to treatment, cells were maintained in RPMI-1640 medium without phenol red and supplemented with 5\% FBS or 5\% dextran-coated, charcoal-treated FBS (stripped serum). Cells were treated with $10 \mathrm{nM}$ E2 (Sigma), 12.5 nM IGF-1 (Sigma), $1 \mu \mathrm{M}$ ICI-182,780 (ICI) (Tocris Cookson Inc., Ballwin, MO), $30 \mu \mathrm{M}$ LY294002 (a PI3-K inhibitor; Calbiochem), or $30 \mu \mathrm{M}$ SB202190 (a p38MAPK inhibitor; Calbiochem) for the indicated times.

Quantitative real-time PCR ( $q P C R$ ). Total-RNA from MCF-7 cells was extracted by the acid guanidinium thiocyanatephenol-chloroform method (28) and cDNA synthesis was carried out using the High Capacity Archive kit (Applied Biosystems). PAR-4 mRNA levels were measured by real-time PCR using GAPDH as the internal standard. Real-time PCR was performed using the SYBR-Green master mix kit (Applied Biosystems) and processed in the GeneAmp 5700 Sequence Detection system (Applied Biosystems). The oligonucleotides used were: GAPDH, forward 5'-CCTCCAAAATCAAG TGGGGCG-3', reverse 5'-GGGGCAGAGATGATGACC CTT-3'; PAR-4, forward 5'-CCAGAGAAGGGCAAGAGCT CGG-3', reverse 5'-ATTGCATCTTCTCGTTTCCGC-3'. The relative gene expression was calculated by $2^{-\Delta \Delta C T}$ where $C T$ is the fluorescence threshold value. $\Delta \mathrm{CT}=\mathrm{CT}_{\text {target gene }}-\mathrm{CT}_{\text {reference }}$ gene (GADPH) $; \Delta \Delta \mathrm{CT}, \Delta \mathrm{CT}_{\text {target sample }}-\Delta \mathrm{CT}_{\text {reference sample (cells maintained in }}$ $5 \% \mathrm{FBS})$. The results were expressed as $\mathrm{n}$-fold differences in the mRNA expression relative to the expression of GAPDH and the reference sample.

Western blot analysis. For Western blotting, whole-cell lysates were prepared from MCF-7 cells after the treatments, and $30 \mu \mathrm{g}$ were analyzed on $10 \%$ SDS-polyacrylamide gels followed by transfer at $100 \mathrm{~V}$ for $2 \mathrm{~h}$ to a nitrocellulose membrane
(Pierce Biotechnology, Rockford, IL, USA). Blots were incubated with anti-PAR-4 monoclonal antibody (Santa Cruz Biotechnology Inc., Santa Cruz, CA, USA, catalog sc-1666; 1:500); anti-pAKT Thr 308 (Cell Signaling Technology, Beverly, MA, USA; $1: 1000$ ); and anti- $\beta$-actin antibody (Chemicon International; $1: 1000)$, for $2 \mathrm{~h}$ at room temperature. Membranes were washed and then incubated with an appropriate peroxidaseconjugated secondary IgG antibody for $2 \mathrm{~h}$. The incubations were performed in 5\% skim milk diluted in PBS. After washing the membranes with Tris-buffered saline containing $0.1 \%$ Tween-20, the signals of reactive proteins were detected by an enhanced chemiluminescence system (Amersham Biosciences, Piscataway, NJ, USA).

Cell proliferation assay. Cell viability was measured using the 3-[4,5-dimethylthiazolyl]-2,5-diphenyltetrazolium bromide (MTT, Sigma) assay. Cells (1x104/well) were seeded in 96-well plates and maintained in RPMI-1640 medium without phenol red and supplemented with 5\% FBS or 5\% dextran-coated charcoal-treated FBS (stripped serum) for $48 \mathrm{~h}$ prior to treatment. Cell viability was assessed on days $0,2,4$ and 6 post-treatment with $10 \mathrm{nM}$ E2 $12.5 \mathrm{nM}$ IGF-1, $1 \mu \mathrm{M}$ ICI by measuring the rate of tetrazolium salts reduced to formazan (MTT), which is proportional to the number of living cells. At the end of incubation, the absorbance was read at $570 \mathrm{~nm}$.

Imunocytochemistry. Cells were fixed with $4 \%$ paraformaldehyde and permeabilized with $0.5 \%$ Triton X-100. Next, cells were incubated with the primary monoclonal anti-PAR-4 antibody (Santa Cruz Biotechnology Inc., catalog sc-1666; 1:50) followed by secondary antibody conjugated with the fluorescent dye Alexa Fluor 546 (Invitrogen; 1:300). Nuclei were counterstained with Hoechst 33342 (Invitrogen; 1:5000). Cells were visualized with the Carl Zeiss LSM 510 Meta (Oberkochen, Germany) laser scanning confocal microscope. All immunofluorescence images were recorded at x20 magnification.

Statistical analysis. The Student's t-test was used for statistical analysis and P-values $<0.05$ were considered to be statistically significant. Values are expressed as the mean \pm SD of three or more replicate experiments.

\section{Results}

To investigate the effects of E2 on the regulation of PAR-4 expression, MCF-7 cells were maintained in serum free from estrogens and growth factors (stripped serum) for $48 \mathrm{~h}$ and then treated with $10 \mathrm{nM}$ E2. The withdrawal of estrogens and grow th factors from the serum resulted in significantly increased PAR-4 expression when compared with the expression observed in control cells (MCF-7 maintained in culture media supplemented with 5\% FBS) (Fig. 1).

Treatment with E2 inhibited PAR-4 expression in a timedependent manner. After $24 \mathrm{~h}$ of treatment, E2 efficiently reverted the stripped serum effect $(\mathrm{P}<0.05)$ and reduced PAR-4 expression to levels similar to those observed in the control cells (Fig. 1). To evaluate whether E2 inhibition of PAR-4 expression was dependent on ER activation, the cells were pre-treated for $1 \mathrm{~h}$ with $1 \mu \mathrm{M}$ fulvestrant (ICI) prior to 
A

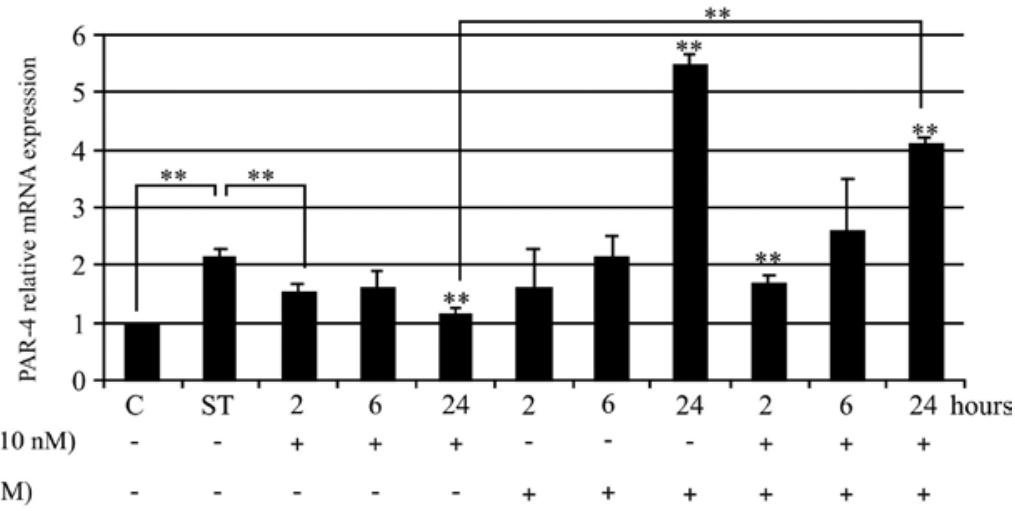

B

$\begin{array}{lllll}\text { Normal Serum }(5 \%) & + & - & - & - \\ \text { Stripped serum }(5 \%) & - & + & + & + \\ 17 \beta \text {-estradiol }(10 \mathrm{nM}) & - & - & + & + \\ \text { ICI } 182,780(1 \mu \mathrm{M}) & - & - & - & +\end{array}$

Figure 1. Effects of 17ß-estradiol (E2) and ICI-182,780 (ICI) on PAR-4 expression. (A) PAR-4 relative mRNA expression was determined by real-time PCR and the results are expressed as the mean \pm SD (bars) from three different experiments. C, MCF-7 cells grown in 5\% FBS; ST, MCF-7 cells grown in 5\% stripped serum for $48 \mathrm{~h}$ alone or in combination with E2 and/or ICI. Statistically significant differences between the groups are indicated by asterisks. ${ }^{*} \mathrm{P}<0.05 ;{ }^{* *} \mathrm{P}<0.01$ when compared with untreated cells in $\mathrm{ST}$ or as indicated. (B) Western blot analysis of protein extracts from MCF-7 cells mantained in medium supplemented with normal serum (FBS 5\%), medium supplemented with stripped serum (stripped FBS 5\%), or stripped serum alone for $48 \mathrm{~h}$ followed by treatment with E2 $(10 \mathrm{nM})$ alone or in combination with ICI $(1 \mu \mathrm{M})$ for $24 \mathrm{~h}$. Protein expression was analyzed with mouse monoclonal anti-PAR-4 antibody (Santa Cruz Biotechnology) and $\beta$-actin antibody (Chemicon International) for normalization.

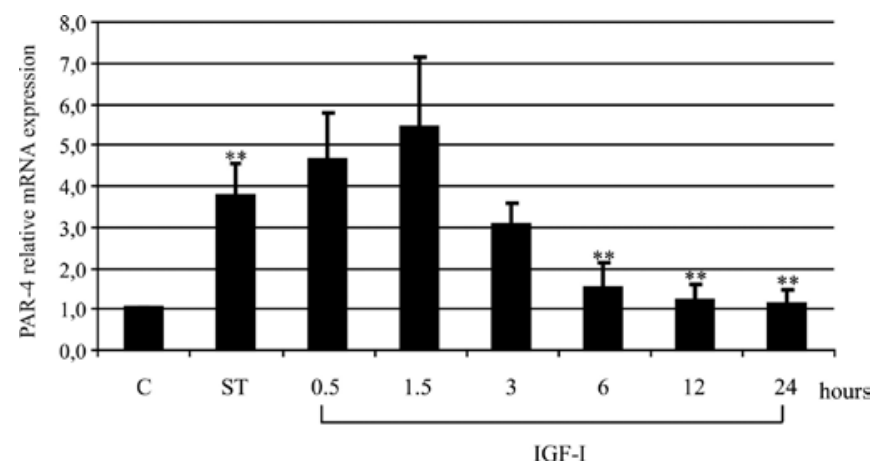

Figure 2. IGF-1 mediates time-dependent PAR-4 gene expression in MCF-7 breast cancer cells. Relative expression was analyzed by real-time PCR and the results are expressed as the mean $\pm \mathrm{SD}$ (bars) from three different experiments. C, MCF-7 cells grown in 5\% FBS; ST, MCF-7 cells grown in $5 \%$ stripped FBS for $48 \mathrm{~h}$ alone and in combination with IGF-1 (12.5 $\mathrm{nM})$. Statistically significant differences between the groups are indicated by asterisks. ${ }^{*} \mathrm{P}<0.05 ;{ }^{* *} \mathrm{P}<0.01$ when compared with untreated cells in ST or as indicated.

treatment with E2 plus ICI. The pure antiestrogen, ICI, inhibits ER activation and induces its degradation (16). We observed complete inhibition of E2 effects by ICI with a significant increase in PAR-4 expression (Fig. 1), providing evidence that E2 regulates PAR-4 expression via ER activation.

Next, we studied the regulation of PAR-4 expression in MCF-7 cells by IGF-1. Cells maintained in stripped serum for $48 \mathrm{~h}$ were treated with $12.5 \mathrm{nM}$ IGF-1 for the indicated times. IGF-1 also modulated PAR-4 expression in a time-dependent manner. After slight increases at 0.5 and $1.5 \mathrm{~h}$ of IGF-1 exposure, PAR-4 mRNA expression was progressively reduced, until it reached its lowest level at $24 \mathrm{~h}$ of IGF-1 treatment $(\mathrm{P}<0.05$, compared with stripped serum) (Fig. 2).

To investigate which pathways mediate the observed effect of IGF-1 on PAR-4 gene expression, MCF-7 cells maintained in stripped serum for $48 \mathrm{~h}$ were pre-treated for $1 \mathrm{~h}$ with $30 \mu \mathrm{M}$ LY294002 (a PI3-K inhibitor) or $30 \mu \mathrm{M}$ SB202190 (a p38MAPK inhibitor) followed by $12.5 \mathrm{nM}$ IGF-1 for $24 \mathrm{~h}$ (the inhibitors were maintained in the medium). Pre-treatment with LY294002 completely inhibited IGF-1 repression of PAR-4 gene expression $(\mathrm{P}<0.05)$, resulting in increased PAR-4 mRNA expression (Fig. 3A). However, this effect was not observed for PAR-4 protein expression. Although MCF-7 cells treated with IGF-1 showed increased levels of phosphorylated AKT, treatment with LY294002 $(30 \mu \mathrm{M})$ was insufficient to abolish the inhibitory effect of IGF-1 on PAR-4-repressed protein expression (Fig. 3C), suggesting that other factors may also be important for the translational regulation of PAR-4. Pre-treatment with SB202190 also inhibited the effect of IGF-1, but was less effective than LY294002 pre-treatment. These results suggest that the PI3-K pathway is one of the pathways through which IGF-1 inhibits PAR-4 transcriptional regulation.

We also evaluated whether E2 and IGF-1 could act synergistically on the inhibition of PAR-4 mRNA expression. MCF-7 cells were treated with $10 \mathrm{nM}$ E2 and 12.5 nM IGF-1, either alone or in combination, for $24 \mathrm{~h}$, or pre-treated for $1 \mathrm{~h}$ with $1 \mu \mathrm{M}$ ICI followed by $12.5 \mathrm{nM}$ IGF-1 plus ICI for $24 \mathrm{~h}$. Treatment with E2 plus IGF-1 resulted in significantly greater 
A

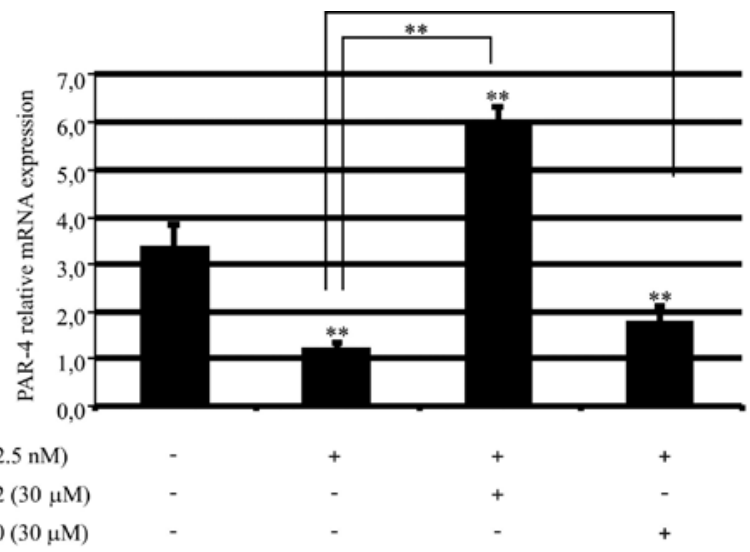

B

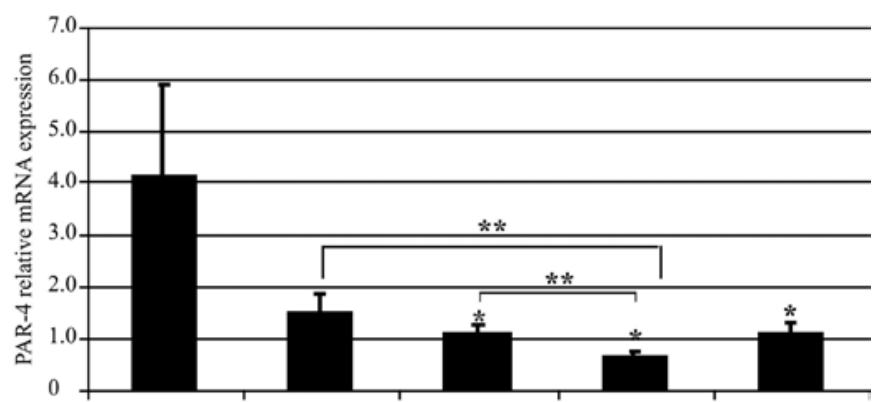

$17 \beta$-estradiol $(10 \mathrm{nM})$

IGF -I (12.5nM)

ICI $182,780(1 \mu \mathrm{M})$

$\mathrm{C}$

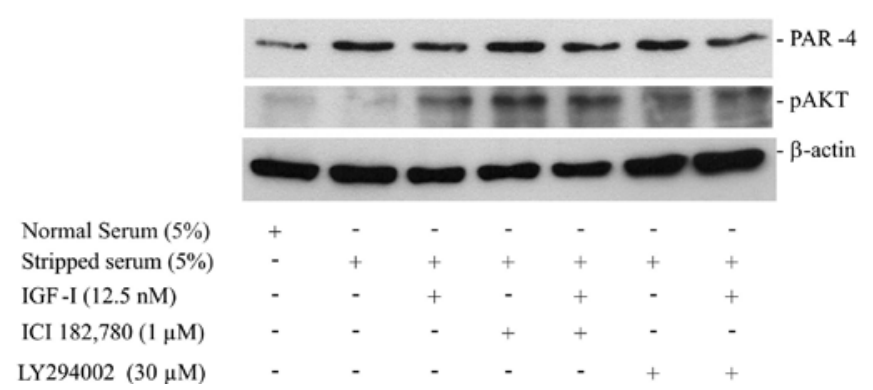

Figure 3. Regulation of PAR-4 expression by $\beta$-estradiol (E2) and IGF-1 in MCF-7 breast cancer cells. (A) Effects of LY294002 (LY) or SB202190 (SB) on PAR-4 expression regulated by IGF-1. MCF-7 cells grown in 5\% stripped FBS for $48 \mathrm{~h}$ and after treatment with IGF alone and in combination with the inhibitors LY or SB for $24 \mathrm{~h}$. (B) E2 and IGF-1 have a synergistic effect on PAR-4 mRNA expression in MCF-7 breast cancer cells. MCF-7 cells grown in 5\% stripped serum FBS for $48 \mathrm{~h}$ and after treatment with E2, IGF and ICI-182,780 (ICI) (alone or in combination) for $24 \mathrm{~h}$. Relative expression was analyzed by real-time PCR and the results are expressed as the mean \pm SD (bars) from three different experiments. Statistically significant differences between the groups are indicated by asterisks. " $\mathrm{P}<0.05 ;{ }^{* *} \mathrm{P}<0.01$ when compared with untreated cells or as indicated. (C) Western blot analysis of PAR- 4 and pAKT Thr308 from protein extracts from MCF-7 cells grown in normal serum (FBS 5\%), or in 5\% stripped FBS for $48 \mathrm{~h}$, and after treatments with IGF-1 alone or in combination with ICI $(1 \mu \mathrm{M})$, or LY $(30 \mu \mathrm{M})$. Protein expression was analyzed with mouse monoclonal anti-PAR-4 antibody (Santa Cruz Biotechnology), anti-pAKT Thr308 antibody (Cell Signaling Technology), and $\beta$-actin antibody (Chemicon International) for normalization.

inhibition of PAR-4 expression compared with the effects of E2 or IGF-1 alone (Fig. 3B). MCF-7 cells treated with ICI $(1 \mu \mathrm{M})$ for $24 \mathrm{~h}$ showed increased levels of PAR-4 and phosphorylated AKT (Fig. 3C). However, pre-treatment with ICI did not interfere with the IGF-1 regulation of PAR-4 expression. Therefore, the E2 and IGF-1 combination treatment had a synergistic effect on PAR-4 expression and this synergy was not a result of ER activation by IGF-1. Here, we also evaluated the effects of E2 and IGF-1 on MCF-7 cell viability and proliferation. MCF-7 cells maintained in medium supplemented with stripped serum (starved for growth factors and estrogen), which displayed elevated PAR-4 expression, also showed proliferative restraint (Fig. 4). MCF-7 cells treated with E2 and IGF-1 showed significant induction of cell proliferation compared with cells maintained in stripped serum. The mitogenic effects of E2 were completely abolished with ICI followed by treatment with E2 plus ICI. However, as found for PAR-4 expression, the mitogenic effect of IGF-1 was not inhibited by the presence of ICI.

PAR-4 protein expression was predominantly localized in the nucleus of MCF-7 cells and was down-regulated after treatment for $24 \mathrm{~h}$ with E2 and IGF-1 (Fig. 5). 


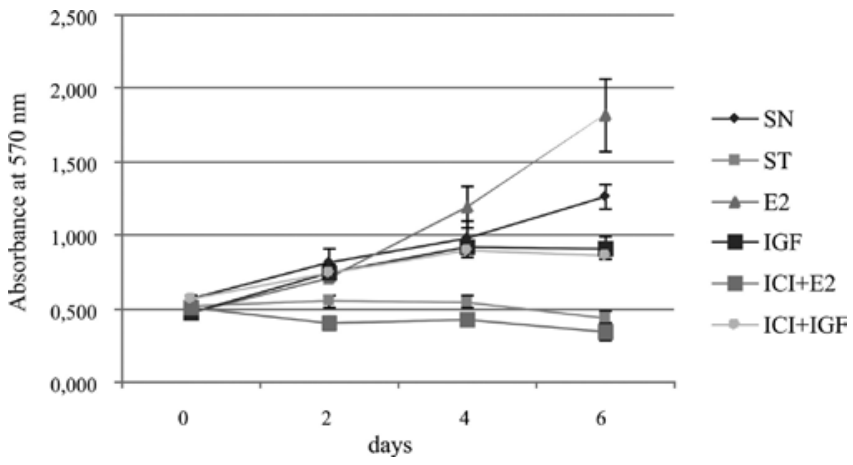

Figure 4. E2 and IGF-1-induced proliferation of MCF-7 breast cancer cells. MCF-7 cells ( $1 \times 10^{4}$ cells) were seeded in 96-well plates and maintained in medium without phenol red supplemented with stripped FBS (5\%) for $48 \mathrm{~h}$, and then treated with $17 \beta$-estradiol $(\mathrm{E} 2 ; 10 \mathrm{nM})$ or IGF-1 $(12.5 \mathrm{nM})$ alone or in combination with ICI-182,780 $(1 \mu \mathrm{M})$. Cell viability was measured by the MTT assay as described in the Materials and methods. The experiments were performed in triplicate and the values are presented as the mean absorbance $(\mathrm{OD}, 570 \mathrm{~nm}) \pm \mathrm{SD}$.
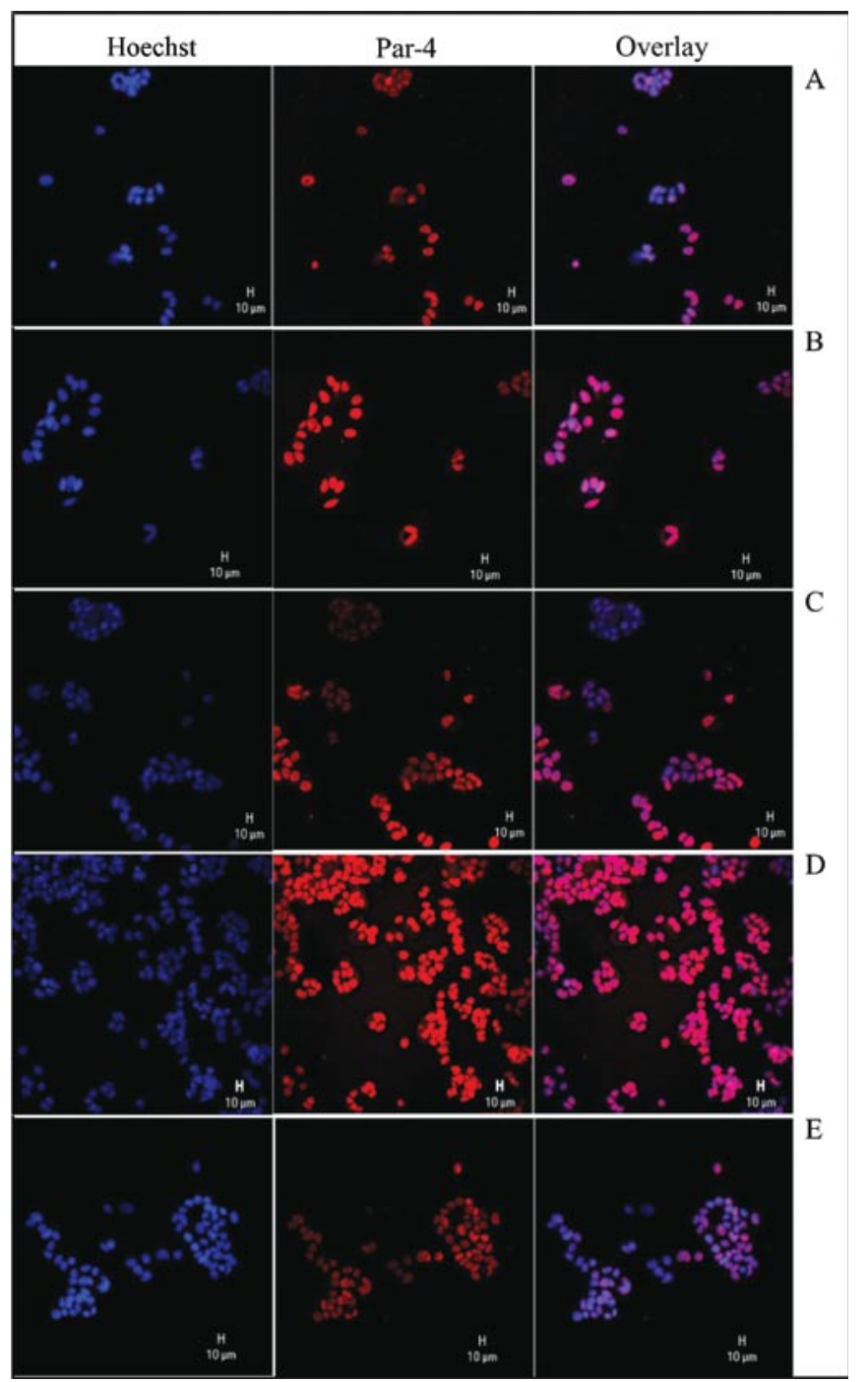

Figure 5. Immunocytochemical analysis of PAR-4 protein expression in MCF-7 breast cancer cells. MCF-7 cells grown (A) in 5\% FBS or (B-E) in

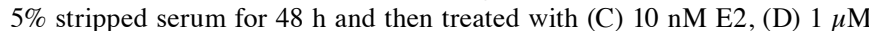
ICI, and (E) $12.5 \mathrm{nM}$ IGF for $24 \mathrm{~h}$, fixed, and probed with PAR-4 antibody to detect the expression of endogenous PAR-4. Nuclei were visualized by staining with Hoechst (blue). Intracellular localization of PAR-4 (in red) was recorded by confocal microscopy at x 20 magnification.

\section{Discussion}

In the present study we sought to investigate the effects of E2 and IGF-1 on PAR-4 expression in the MCF-7 breast cancer cell line. We showed that E2 and IGF-1 inhibit PAR-4 mRNA and protein expression in MCF-7 cells. In addition, ER activation by $\mathrm{E} 2$ is essential for the observed effect of E2, and the PI3-K pathway is one of the IGF-1-activated pathways that regulates PAR-4 mRNA expression. In addition, E2 acts synergistically with IGF-1 to regulate PAR-4 mRNA expression in MCF-7; however, this synergy does not depend on ER activation by IGF-1.

Tissue homeostasis is obtained through the proper balance of signals that induce cell death and proliferation. Apoptosis is an essential mechanism for maintaining tissue homeostasis, and resistance to apoptosis contributes to malignant cellular transformation (29). PAR-4 is an early gene-induced in response to apoptotic stimulation (5). PAR-4 pro-apoptotic action involves activation of the Fas/FasL pro-death pathway (10) and inactivation of the NF- $\mathrm{KB}$ pro-survival pathway $(12,13)$. In addition, phosphorylation of the T155 residue in the PAR-4 SAC domain by PKA (9) and PAR-4 translocation to the nucleus (11) are essential for apoptosis.

Treatment of MCF-7 cells with IGF-1 results in downregulation of PAR-4 transcripts. IGF-1 acts primarily through binding to the IGF-1R at the cell surface, which results in activation of the intrinsic tyrosine kinase receptor activity of the receptor, auto-phosphorylation of its tyrosine residues, and recruitment and phosphorylation of adaptor signaling proteins. However, the major pathway activated by IGF-1R signaling is that of PI3-K, which regulates proliferation and, most importantly, resistance to apoptosis (30). When the PI3-K pathway is activated, AKT phosphorylates PAR-4 at the S249 residue; as a consequence, PAR-4 is bound by 14-3-3 proteins and is sequestered in the cytoplasm (11). Our findings provide evidence that AKT is, at least in part, one of the mediators of the IGF-1 pathway that leads to PAR-4 inhibition and cell survival in MCF-7 breast cancer cells. Accordingly, Chung et al (26) reported that IGF-1 inhibited PAR-4 expression in PC12 cells in a MAPK- and PI3-K-dependent manner, and that IGF-1 inhibition of PAR-4 expression protected PC12 cells from apoptosis.

Here, we have for the first time demonstrated that PAR-4 is an estrogen-responsive gene in breast cancer cells. Estrogens regulate growth, differentiation, and tissue homeostasis through ER activation. Breast cancer progression is associated with a deregulated response to the ER, resulting in an increased proliferative response of ER-positive breast epithelial cells $(31,32)$. Recently, we have shown that nuclear PAR-4 downregulation is a frequent event associated with poor breast cancer prognosis, also observed in the luminal A breast cancer subtype (27). Experimental studies have demonstrated that PAR-4 is localized in the nucleus of most cancer cell lines, and that PAR-4 nuclear entry is required to induce apoptosis $(33,34)$. Previous research has also shown that hormonedependent prostate and breast cancer cell lines, such as LNCaP and MCF-7, are resistant to PAR-4 induced apoptosis $(9,35)$. E2 inhibition of PAR-4 mRNA expression in MCF-7 cells leads to reduced PAR-4 protein expression and contributes to the prevalence of cell proliferation, possibly due to the 
resistance of MCF-7 cells to PAR-4-induced apoptosis. A report that E2 treatment of hippocampal neurons in culture inhibited apoptosis induced by PAR-4 after trophic factor withdrawal supports this hypothesis (25). Furthermore, our findings suggest that PAR-4 expression induced by growth factor and estrogen starvation may lead to growth arrest, but is insufficient to induce apoptosis in MCF-7 cells.

Moreover, IGF-1 may activate the ER through a ligandindependent mechanism, and E2 may increase mRNA expression of the IGF-1R and other signaling proteins from the IGF-1R pathway. This crosstalk between the ER and IGF-1 results in synergistic effects causing increased cell proliferation. Therefore, the synergy observed between E2 and IGF-1 with respect to the inhibition of PAR-4 expression may contribute to mechanisms by which these factors induce breast cancer cell survival due to a possible inhibition of apoptosis.

In this study, we report that PAR-4 expression is downregulated by E2 and IGF-1 in the breast cancer cell line MCF-7. Although further experimental studies are required, our data suggest that PAR-4 down-regulation by E2 and IGF-1 in MCF-7 breast cancer cells contributes to cell survival promoted by these mitogenic factors.

\section{Acknowledgements}

This study was supported by FAPESP - Fundação de Amparo a Pesquisa do Estado de São Paulo (06/01026-0). This study was also supported in part by $\mathrm{CNPq}$ (Conselho Nacional de Desenvolvimento Científico e Tecnológico; 304949/2006-0).

\section{References}

1. Sells SF, Wood DP Jr, Joshi-Barve SS, et al: Commonality of the gene programs induced by effectors of apoptosis in androgendependent and -independent prostate cells. Cell Growth Differ 5: 457-466, 1994

2. Cook J, Krishnan S, Ananth S, et al: Decreased expression of the pro-apoptotic protein Par-4 in renal cell carcinoma. Oncogene 18: 1205-1208, 1999.

3. Kögel D, Reimertz C, Mech P, et al: Dlk/ZIP kinase-induced apoptosis in human medulloblastoma cells: requirement of the mitochondrial apoptosis pathway. Br J Cancer 85: 1801-1808, 2001.

4. Boehrer S, Chow KU, Puccetti E, et al: Deregulated expression of prostate apoptosis response gene-4 in less differentiated lymphocytes and inverse expressional patterns of par- 4 and bcl-2 in acute lymphocytic leukemia. Hematol J 2: 103-107, 2001.

5. Sells SF, Han SS, Muthukkumar S, et al: Expression and function of the leucine zipper protein Par-4 in apoptosis. Mol Cell Bio 17: 3823-3832, 1997

6. El-Guendy N and Rangnekar VM: Apoptosis by Par-4 in cancer and neurodegenerative diseases. Exp Cell Res 283: 51-66, 2003.

7. Goswami A, Ranganathan P and Rangnekar VM: The phosphoinositide 3-kinase/Akt1/Par-4 axis: a cancer-selective therapeutic target. Cancer Res 66: 2889-2892, 2006.

8. Burikhanov R, Zhao Y, Goswami A, Qiu S, Schwarze SR and Rangnekar VM: The tumor suppressor Par-4 activates an extrinsic pathway for apoptosis. Cell 138: 377-388, 2009.

9. Gurumurthy S, Goswami A, Vasudevan KM and Rangnekar VM Phosphorylation of Par-4 by protein kinase A is critical for apoptosis. Mol Cell Biol 25: 1146-1161, 2005.

10. Chakraborty M, Qiu SG, Vasudevan KM and Rangnekar VM: Par-4 drives trafficking and activation of Fas and Fasl to induce prostate cancer cell apoptosis and tumor regression. Cancer Res 61: 7255-7263, 2001.

11. Goswami A, Burikhanov R, de Thonel A, et al: Binding and phosphorylation of Par- 4 by Akt is essential for cancer cell survival. Mol Cell 20: 33-44, 2005.
12. Diaz-Meco MT, Lallena MJ, Monjas A, Frutos S and Moscat J: Inactivation of the inhibitory $\kappa \mathrm{B}$ protein kinase/Nuclear factor $\kappa \mathrm{B}$ pathway by Par-4 expression potentiates tumor necrosis factor a-induced apoptosis. J Biol Chem 274: 19606-19612, 1999.

13. Nalca A, Qiu SG, El-Guendy N, Krishnan S and Rangnekar VM: Oncogenic Ras sensitizes cells to apoptosis by Par-4. J Biol Chem 274: 29976-29983, 1999.

14. Parkin DM, Bray F, Ferlay J and Pisani P: Global cancer statistics 2002. CA Cancer J Clin 55: 74-108, 2005.

15. Parkin DM and Fernández LM: Use of statistics to assess the global burden of breast cancer. Breast J 12 (Suppl 1): S70-S80, 2006.

16. Howell A: Pure oestrogen antagonists for the treatment of advanced breast cancer. Endocr Rel Cancer 13: 689-706, 2006.

17. Nagai MA and Brentani MM: Gene expression profiles in breast cancer to identify estrogen receptor target genes. Mini Rev Med Chem 8: 448-454, 2008.

18. Altucci L, Addeo R, Cicatiello L, et al: 17beta-estradiol induces cyclin D1 gene transcription, p36D1-p34cdk4 complex activation and $\mathrm{p} 105 \mathrm{Rb}$ phosphorylation during mitogenic stimulation of G(1)-arrested human breast cancer cells. Oncogene 12: 2315-2324, 1996.

19. Foster JS and Wimalasena J: Estrogen regulates activity of cyclindependent kinases and retinoblastoma protein phosphorylation in breast cancer cells. Mol Endocrinol 10: 488-498, 1996.

20. Foster JS, Henley DC, Ahamed S and Wimalasena J: Estrogens and cell-cycle regulation in breast cancer. Trends Endocrinol Metab 12: 320-327, 2001.

21. Bartucci M, Morelli C, Mauro L, Andò S and Surmacz E: Differential insulin-like growth factor I receptor signaling and function in estrogen receptor (ER)-positive MCF-7 and ER-negative MDA-MB-231 breast cancer cells. Cancer Res 61: 6747-6754, 2001.

22. Jones RA, Campbell CI, Gunther EJ, et al: Transgenic overexpression of IGF-IR disrupts mammary ductal morphogenesis and induces tumor formation. Oncogene 26: 1636-1644, 2007.

23. Zhang S, Li X, Burghardt R, Smith R III and Safe SH: Role of estrogen receptor (ER) alpha in insulin-like growth factor (IGF)I-induced responses in MCF-7 breast cancer cells. J Mol Endocrinol 35: 433-447, 2005

24. Sisci D and Surmacz E: Crosstalk between IGF signaling and steroid hormone receptors in breast cancer. Curr Pharm Des 13: 1-13, 2007.

25. Chan SL, Tammariello SP, Estus S and Mattson MP: Prostate apoptosis response-4 mediates trophic factor withdrawal-induced apoptosis of hippocampal neurons: actions prior to mitochondrial dysfunction and caspase activation. J Neurochem 73: 502-512, 1999.

26. Chung H, Seo S, Moon M and Park S: IGF-I inhibition of apoptosis is associated with decreased expression of prostate apoptosis response-4. J Endocrinol 194: 77-85, 2007.

27. Nagai MA, Gerhard R, Salaorni S, Fregnani JH, Nonogaki S, Netto MM and Soares FA: Down-regulation of the candidate tumor suppressor gene PAR-4 is associated with poor prognosis in breast cancer. Int J Oncol 37: 41-49, 2010.

28. Chomczynski P and Sacchi N: Single-step method of RNA isolation by acid guanidinium thiocyanate-phenol-chloroform extraction. Anal Biochem 192: 156-159, 1987.

29. Hanahan D and Weinberg RA: The hallmarks of cancer. Cell 100: 57-70, 2000.

30. Surmacz E and Bartucci M: Role of estrogen receptor alpha in modulating IGF-I receptor signaling and function in breast cancer. J Exp Clin Cancer Res 23: 385-394, 2004.

31. Heldring N, Pike A, Andersson S, et al: Estrogen-receptors: how do they signal and what are their targets. Physiol Rev 87: 905-931, 2007.

32. Stoll BA: Oestrogen/insulin-like growth factor-I receptor interactions in early breast cancer: clinical implications. Ann Oncol 13: 191-196, 2002

33. Gurumurthy S and Rangnekar VM: Par-4 inducible apoptosis in prostate cancer cells. J Cell Biochem. 91: 504-512, 2004.

34. Shrestha-Bhattarai $T$ and Rangnekar VM: Cancer-selective apoptotic effects of extracellular and intracellular Par-4. Oncogene 29: 3873-3880, 2010.

35. El-Guendy N, Zhao Y, Gurumurthy S, Burikhanov R and Rangnekar VM: Identification of a unique core domain of par-4 sufficient for selective apoptosis induction in cancer cells. Mol Cell Biol 23: 5516-5525, 2003. 